\title{
Notum Protects Against Myocardial Infarction- Induced Heart Dysfunction By Alleviating Cardiac Fibrosis
}

\section{Wei Su}

Harbin Medical University

\section{Ruonan Fang}

Harbin Medical University

Yue Li

Harbin Medical University

Liangliang $\mathbf{L i}$

Harbin Medical University

Jing Zhang

Harbin Medical University

Xin Lv

Harbin Medical University

$\mathrm{Na}$ Yang

Harbin Medical University

Qianqian Wang

Harbin Medical University

Guofang Zhang

Harbin Medical University

Xuelian Li

Harbin Medical University

Hongli Shan

Harbin Medical University

Tianyu Li ( $\boldsymbol{\sim}$ Lity@hrbmu.edu.cn )

Harbin Medical University https://orcid.org/0000-0001-9837-1042

\section{Research Article}

Keywords: Cardiac Fibrosis, Notum, Wnt/ $\beta$-catenin, Senescence, myocardial infarction

Posted Date: November 9th, 2021

DOI: https://doi.org/10.21203/rs.3.rs-1023805/v1 
License: (c) (i) This work is licensed under a Creative Commons Attribution 4.0 International License. Read Full License 


\section{Abstract}

Cardiac fibrosis is a pathological reparative process that occurs subsequent to myocardial injury. It is associated with cardiac systolic and diastolic dysfunction and reduced cardiac compliance that eventually leads to heart failure. Delaying or inhibiting the progression of pathological myocardial fibrosis is of great significance for the treatment of many cardiovascular diseases. The Wnt signaling pathway is closely related to the occurrence of organ fibrosis, and Notum is a highly conserved secreted feedback inhibitor of Wnt signaling. It has been shown that Notum acts as a regulator in many organs, such as the aging intestinal epithelium, adult ventricular-subventricular zone neurogenesis, and mouse tooth root development. However, the role and mechanism of Notum on cardiac fibrosis are not well-understood. In this study, we found that Notum significantly increased survival rate and improved cardiac function following myocardial infarction in mice. More importantly, Notum inhibited the Wnt/ $\beta$-catenin signaling pathway and senescence of cardiac fibroblasts, thereby decreasing the activation of cardiac fibroblasts, reducing the excessive deposition of extracellular matrix, and ultimately inhibiting the occurrence of cardiac fibrosis. Taken together, our findings demonstrated the anti-fibrotic effects of Notum on maladaptive cardiac fibrosis, and suggest that it may be a new strategy for the treatment of cardiac fibrosis.

\section{Introduction}

Cardiac fibrosis, an abnormal reparative process in response to cardiomyocyte injury, is associated with nearly all types of heart disease, including hypertrophic cardiomyopathy, myocardial infarction, and dilated cardiomyopathy[1, 2]\{!!! INVALID CITATION !!! 1`,2, ;Heymans, 2015 \#2\}. In a persistent disease state or with abnormal activation of various pathways, this pathological myocardial remodeling contributes to arrhythmias, increases myocardial stiffness, and causes ventricular dysfunction. Thus, cardiac fibrosis is considered a key contributor to heart failure[3, 4].

Cardiac fibrosis is characterized by the excessive deposition of extracellular matrix (ECM) and formation of scar tissue. Cardiac fibroblasts are an essential cell type in the heart and a primary source of components of the ECM. Upon injury, fibroblasts are activated abnormally, with enhanced migration capacity, excessive proliferation, and transformation to a myofibroblast phenotype. This results in the accumulation of ECM, thus reducing tissue compliance and inducing myocardial remodeling[5-7]. Previous studies confirmed that cardiomyocyte death or various adverse stimulations caused by ischemia, hypertension, aging, anthracyclines, and many other pathological conditions can augment the occurrence of cardiac fibrosis[8-10]. Therefore, inhibiting or delaying the progression of cardiac fibrosis is important for the prevention and treatment of cardiovascular diseases.

Recent studies have found that various types of cellular effectors, such as macrophages, mast cells, and lymphocytes, can activate the profibrotic pathway by producing matrix proteins or secreting mediators[11]. Meanwhile, inflammatory signaling, the Renin-Angiotensin-Aldosterone System, transforming growth factor- $\beta$ (TGF- $\beta$ ), and other molecular pathways play important roles in the 
occurrence and development of fibrosis[12-14]. However, the pathogenesis of cardiac fibrosis still needs in-depth study, and there are currently limited means to effectively reduce or reverse this process.

Wnt pathway plays an important role in the development and homeostasis of many organs, including liver and heart $[15,16]$. Numerous studies have shown that the Wnt pathway participates in the process of organ fibrosis, such as cardiac fibrosis[17-20], renal fibrosis[21], etc. The results from Yang et al. found that CGX1321 administration blocked the secretion of Wnt proteins, inhibited both canonical and noncanonical Wnt signaling pathways, then reduced myocardial infarct size and fibrosis, and finally improved cardiac function in MI mice[16]. Qian et al. found that downregulation of S100A4 alleviates cardiac fibrosis via Wnt/ $\beta$-catenin pathway in mice[22]. In addition, Jeong and colleagues found that Cdon deficiency causes hyperactive Wnt signaling leading to aberrant intercellular coupling and cardiac fibrosis[23].

Notum, an endogenous feedback inhibitor of the Wnt signaling pathway, is a carboxylesterase with the specific activity of deacylating Wnts by removing an essential palmitoleic moiety[24]. Pentinmikko et al. confirmed that senescent Paneth cells can produce Notum and inhibit the regeneration of aging intestinal epithelial cells. In addition, inhibiting Notum in mice can enhance the regeneration ability of aging stem cells and promote the regeneration of aging tissue[25]. However, whether Notum can regulate cardiac fibrosis, and through what kind of mechanism, has not been confirmed.

In this study, we determined the cardioprotective effect of Notum in mice with myocardial infarction and preliminarily clarified the mechanisms by which Notum exerted an anti-fibrotic effect in the myocardium. These results support a new strategy for the prevention and treatment of myocardial fibrosis.

\section{Material And Methods}

\subsection{Animal model and treatment}

The procedures for the use of animals in this work were in accordance with the regulations of the Ethic Committees of Harbin Medical University, and conformed to the Guide for the Care and Use of Laboratory Animals published by the US National Institutes of Health (NIH Publication No. 85-23, revised 1996). Adult male C57BL/ 6 mice which the mean weight is $25 \mathrm{~g}$ were purchased from Changsheng Biotechnology (Liaoning, China) and randomly divided into three groups: sham, MI, Ml+notum. All the mice were anesthetized with avertin $(240 \mathrm{mg} / \mathrm{kg}$, intraperitoneal [i.p.]). The trachea was cannulated and ventilated with a small animal ventilator at a tidal volume of $3 \mathrm{ml}$. MI model was induced by ligation of the left coronary artery. Mice in Ml+notum group were injected with notum $(1 \mu \mathrm{g} / 25 \mathrm{~g})$ from R\&D System (USA) at the basis of MI surgery. Notum drug powder was diluted to 100ng / ul with PBS and was given according to $1 \mathrm{ug} / 25 \mathrm{~g}$ body weight. A $25 \mathrm{~g}$ mouse needs to be injected with $10 \mathrm{ul}$ drug solution. Notum was injected into the heart via intramycoardial delivery way at five sites (upper, lower, left, right, and center)[26].

\subsection{Cell culture}


Primary cardiac fibroblasts were isolated from 2 to 3-day-old Kunming mice. The hearts of the mice were taken out and placed in a petri dish with ice-cold DMEM (Biological Industries, Israel). Then the heart tissues were cut into $1 \mathrm{~mm}$ cubed pieces with sterilized scissors and digested by trypsin $(0.5 \mathrm{mg} / \mathrm{ml})$ completely. The supernatant were centrifuged at $1300 \mathrm{rpm}$ for $7 \mathrm{~min}$ after filtration. Furthermore, the cells were re-suspended in DMEM containing $10 \%$ fetal bovine serum (FBS, Biological Industries) and seeded into culture plates. After $1.5 \mathrm{~h}$, the non-adherent cells were removed. The cardiac fibroblasts (adherent cells) were cultured at $37^{\circ} \mathrm{C}$ with $5 \% \mathrm{CO}_{2}$.

When the density of cardiac fibroblasts reached $70-80 \%, 10 \mathrm{ng} / \mathrm{ml}$ TGF- $\beta 1$ (Sigma-Aldrich, USA) and $10 \mathrm{ng} / \mathrm{ml}$ notum (R\&D System, USA) were added into the cells and incubated for $24 \mathrm{~h}$ before further analysis. In addition, cardiac fibroblasts were treated with $100 \mu \mathrm{mol} / \mathrm{L} \mathrm{H}_{2} \mathrm{O}_{2}$ (Sigma-Aldrich, USA) $2 \mathrm{~h}$ after treatment of notum for $22 \mathrm{~h}$.

\subsection{Western blot}

Protein of heart tissues and cardiac fibroblasts were extracted with RIPA lysis buffer (Beyotime, Jiangsu, China). Protein samples ( 80 or $50 \mu \mathrm{g}$ ) were separated by SDS-PAGE and then transferred to polyvinylidene fluoride membranes (Pall Life Sciences, Ann Arbor, MI, USA). After 2 hours of blocking in $5 \%$ skim milk, the membranes were incubated with primary antibodies at $4^{\circ} \mathrm{C}$ overnight. The next day, these membranes were washed with PBST 3 times and incubated with the secondary antibody for $1 \mathrm{~h}$. The Odyssey Infrared Imaging System was used to scan the membranes. The Western blot results were analyzed by Image Studio Ver 5.2 software.

The information of the antibodies are shown as follows: FN1 (15613-AP, 1:500, Proteintech), collagen 1 (WL0088, 1:500, Wanlei), a-SMA (ab7817, 1:2000, Abcam), p53 (10442-1-AP, 1:500, Proteintech), $\beta$-actin (60008-1-AP, 1:1000, Proteintech), GAPDH (60004-1-Ig, 1:1000, Proteintech).

\section{4. qRT-PCR}

Total RNA was extracted from heart tissues or cardiac fibroblasts using a Trizol standard protocol. The concentration and purity of RNA was detected by Nano-Drop 8000 Spectrophotometer (Thermo, USA). According to the manufacturer's instructions, RNA was reverse transcripted into CDNA with High Capacity cDNA Reverse Transcription Kit (Transgene, AT341-02) and the relative mRNA levels were detected by qRT-PCR with SYBR Green I (Roche, 4913914001). The Ct values were calculated to analyze mRNAs relative levels, and these data were normalized to GAPDH.

\subsection{Histology analysis}

Hearts were fixed in $4 \%$ paraformaldehyde for 3 days before dehydrating, then they were embedded in paraffin and cut into $6 \mu \mathrm{m}$ slices. According to the manufacturer's instructions, the slices were stained with H\&E and Masson's trichrome to evaluate the degree of fibrosis. The fibrotic areas were calculated with Image-Pro plus 6.0 software. 


\subsection{Immunohistochemistry staining}

Dewaxing and rehydrating cardiac sections with dimethylbenzene and gradient ethanol, then these sections were treated with $3 \% \mathrm{H}_{2} \mathrm{O}_{2}$ for 10 min before repairing antigen with Sodium Citrate Buffer in microwave. Sections were blocked with $50 \%$ goat serum at $37^{\circ} \mathrm{C}$ for $1 \mathrm{~h}$ and incubated with primary antibodies against FN1 purchased from Proteintech, $\alpha$-SMA and $\beta$-catenin from Abcam and p16 from Wanlei. HRP conjugated secondary antibodies (ZsBio, Beijing, China) were used to combine with the primary antibodies. Then the sections were stained with DAB (ZsBio) and the nucleus was stained with hematoxylin (Solarbio, China).

\subsection{Immunofluorescence staining}

After treatment of TGF- $\beta 1$ and notum, cardiac fibroblasts were washed with PBS for three times and fixed in $4 \%$ paraformaldehyde for 30 min at temperature. Then the cells were penetrated with $0.4 \%$ Triton X-100 for $1 \mathrm{~h}$ at room temperature, and blocked with $50 \%$ normal goat serum at $37^{\circ} \mathrm{C}$ for $1 \mathrm{~h}$. The cells were washed for three times and incubated with antibody against a-SMA $(1: 200, A b c a m)$ at $4{ }^{\circ} \mathrm{C}$ overnight. The next day, after three times' washing, cells were incubated with FITC-conjugated goat anti-mouse antibody in the dark for $1 \mathrm{~h}$. The nucleuses were stained with DAPI (Roche Molecular Biochemicals). Immunofluorescence was observed with microscope (Olympus, IX73, Japan).

\subsection{Proliferation assay}

Primary cardiac fibroblasts were cultured and treated in 24-well plates, Cell-Light EdU DNA Cell Proliferiation Kit (RiboBio, Guangzhou, China) was used to detect cell proliferation. All experimental procedures were based on manufacturer's instructions. The images were observed with a fluorescence microscope (Olympus, IX73, Japan).

\subsection{Wound-healing Scratch assay}

Scratch assay was performed to evaluate the migration of cardiac fibroblasts. Cells were seeded in 6-well plates, wounds were created by scratching the cell monolayer with $10-\mu l$ pipette tips. Then cells were washed with PBS for two times and treated as indicated for $24 \mathrm{~h}$. Images were captured at $0 \mathrm{~h}, 12 \mathrm{~h}$ and 24h with the Nikon TS100 microscope (Nikon, Japan).And the relative cell migration was analyzed by Image J.

\subsection{Statistical analysis}

Data are presented as mean \pm SEM. One way analysis of variance (ANOVA) followed by Bonferroni or Dunnett's post-hoc test was used for multiple group comparisons. $P<0.05$ was considered statistically significant. Graph Pad Prism 8.0 was used for statistical analyses.

\section{Results}




\subsection{Notum increases survival and improves cardiac function in MI mice}

To investigate the effects of Notum on the heart, C57BL/ 6 mice underwent ligation of the left coronary artery surgery for 7 days to induce myocardial infarction (MI), and Notum was injected into the heart at the same time (Figure 1A). As shown in Figure 1B, the survival rate post-MI was observed up to 7 days post-surgery, which was significantly higher in the Ml+Notum group $(23 / 25 ; 92 \%)$ than that in the MI group $(18 / 25 ; 72 \%)$. Furthermore, cardiac function was tested by echocardiography on 7 day post-MI (Figure 1C), and the data showed that. cardiac systolic dysfunction was significantly noted in MI mice compared to that in Sham group, as evidenced by decreased LVEF囚Sham $52.26 \pm 5.25 \%$ vs. MI $40.38 \pm 4.51 \%$ \and LVFS (Sham $26.11 \pm 3.33 \%$ vs. MI 19.43 $\pm 2.21 \%$ ). However, in Ml+Notum group, the LVEF (57.35 $\pm 11.81 \%)$ and LVFS (30.05 $\pm 7.49 \%)$ were significantly higher in comparison with mice in the $\mathrm{MI}$ group (Figure 1D and 1E). Further analysis of the data reveals that treated with Notum was also associated with significant decreases in LV systolic (MI 43.35 $\pm 17.43 \mu \mathrm{l} v$ s. Ml+Notum 26.54 $\pm 12.57 \mu \mathrm{l}$ ) and diastolic volume (MI 79.10 $\pm 22.08 \mu \mathrm{l} v s$. Ml+Notum $59.30 \pm 14.70 \mu \mathrm{l}$ ) relative to $\mathrm{Ml}$ group (Figure 1F and 1G). These results suggested that treated with Notum could improve cardiac function and attenuate cardiac remodeling in $\mathrm{MI}$ mice model.

\subsection{Notum prevents Ml-induced cardiac fibrosis in mice}

To explore the potential role of Notum on cardiac fibrosis post-Ml, at the 7 day post-operation, the mice hearts were obtained and processed for histological analysis. According to H\&E and Masson staining, compared with the sham group, the myocardial tissue around the infarct region in Ml group was arranged in disorder with a large number of inflammatory cells necrosis and infiltration, but this situation was significantly improved in Notum+Ml group (Figure 2A). Consistently, the Masson staining exhibited less fibrosis areas in the Notum-treated mice when compared to the MI group (Figure 2B).

The transformation of fibroblasts into myofibroblasts is an important feature of fibrosis, a-Smooth muscle actin (a-SMA) and Fibronectin 1 (FN1) are the widely used markers of CF to cardiac myofibroblasts (CMF) differentiation[27, 28]. In our study, the western blot results of cardiac tissue in the infarct border zone showed that the expression of a-SMA and FN1 were significantly up-regulated in MI mice compared with that in sham operation mice, and which could be inhibited after treatment with Notum (Figure 2C). Furthermore, immunohistochemistry assay showed that treated with Notum eliminated the Ml-induced up-regulation of a-SMA and FN1, suggesting that Notum diminished the differentiation of myofibroblasts (Figure 2D and 2E). Meanwhile, compared with the Ml group, the high mRNA levels of FN1, Col 1a1 and Col 3a1 were strikingly reversed in Notum+MI group (Figure. 2F).

\subsection{Notum attenuates cardiac fibroblasts activation induced by TGF- $\beta 1$}

TGF- $\beta 1$ is a classic promotes fibrogenic cytokine, which can cause the transformation of CF to MFs and lead to the deposition of ECM[29]. In vitro, to determine the role of Notum on cardiac fibroblast, primary cultures of cardiac fibroblasts were treated with TGF- $\beta 1$ and TGF- $\beta 1+$ Notum for 24 hours. As shown in Figure $3 \mathrm{~A}$, the addition of Notum could effectively inhibit the high expression of FN1 and the production 
of collagen 1 induced by TGF- $\beta 1$. The results of real-time polymerase chain reaction (RT-PCR) also showed that the addition of Notum could inhibit the up-regulation of FN1, Col 1a1, Col 3a1 and a-SMA at mRNA level induced by TGF- $\beta 1$ (Figure 3B). Moreover, Notum alleviated the TGF- $\beta 1$-induced proliferation of CFs (Figure $3 \mathrm{C}$ ). We used scratch assay to detect the effect of Notum on the migration ability of fibroblasts. As illustrated in Figure3D, the addition of Notum can significantly inhibit the cell migration induced by TGF- $\beta 1$. Furthermore, the expression of a-SMA in cardiac fibroblasts treated with TGF- $\beta 1$ was significantly increased, and the well-organized a-SMA filaments could be clearly seen in immunofluorescence results, indicating the transformation of myofibroblasts. However, Notum could inhibit the TGF- $\beta 1$-induced MF transformation and the overexpression of a-SMA (Figure 3E).

\subsection{Notum inhibits Wnt/ $\beta$-catenin signaling activation in CFs}

To determine the role of the Notum in the process of cardiac fibrosis, we detected whether Notum can inhibit the activation of Wnt/ $\beta$-catenin signal pathway in cardiac fibroblasts in vivo and in vitro. As illustrated in Figure $4 A$, the results of immunohistochemistry staining showed that the expression of $\beta$ catenin was significant increase in the infarcted border zone of MI mice, whereas that was obvious inhibited after Notum injection. Consistent with the immunohistochemistry results, the qRT-PCR and Western blot results also showed that the mRNA and protein level of $\beta$-catenin were strikingly decreased after injection of Notum in MI mice (Figure 4B\&C). Meanwhile, as shown in Figure 4D, treated with Notum abolished TGF- $\beta 1$-induced elected $\beta$-catenin expression, and also the glycogen synthase kinase $3 \beta$ (GSK3 $\beta$ ), an important component of $\beta$-catenin destruction complex[30]. Moreover, Notum reversed the upregulation of mRNA levels of $\beta$-catenin induced by TGF- $\beta 1$ in CFs (Figure. 4E).

\subsection{The effect of Notum on cardiac fibroblasts senescence}

Aging is not a disease but a physiological and pathological process involving attenuated cellular function and weakened stress resistance[31]. The pathological senescence of myocardial fibroblasts after myocardial infarction is one of the key factors inducing fibrosis. In order to further explore the mechanisms of Notum regulating cardiac fibrosis, primary cultured cardiac fibroblasts were treated with $\mathrm{H}_{2} \mathrm{O}_{2}$ for 2 hours. Western blot results showed that the increased expression of p53 revealed the activation of aging pathway. Meanwhile, the upregulation of p53 was significantly reversed when Notum were pretreatment for 22 hours (Figure 5A). In addition, the RT-PCR results showed that, compared with

the $\mathrm{H}_{2} \mathrm{O}_{2}$ group, treated with Notum decreased the expression of the aging markers p21 and p16 at mRNA level (Figure 5B and 5C). Furthermore, as illustrated in Figure 5D, treatment with Notum prevented p16 upregulation in the infarcted border zone of MI mice.

\section{Discussion}

In this study, we evaluated the important role of Notum, and its mechanisms of action, in governing cardiac fibrosis. Our results revealed that, after intervention with Notum, the cardiac function and survival of mice was significantly improved within seven days post-myocardial infarction. Furthermore, we 
showed that Notum inhibited the senescence of cardiac fibroblasts and their pathological transformation into cardiac myofibroblasts, reduced the production of collagen, and blocked activation of the Wnt/ $\beta$ catenin pathway. We preliminarily demonstrated the therapeutic efficacy of Notum in fibroblasts, and in vivo in a mouse model with cardiac fibrosis induced by myocardial infarction. These experimental findings led us to hypothesize that Notum could be considered a new therapeutic strategy for the prevention and treatment of cardiac fibrosis (Figure 6).

Cardiac fibrosis is a pathological condition that occurs after injury and during aging and is present in almost all types of heart disease. It is caused by the excessive net accumulation of ECM, resulting in cardiac interstitial dilatation, decreased compliance, arrhythmias, and heart failure[8]. Currently, there are no effective antifibrotic therapies that specifically target the cardiac fibroblast[32]. In recent years, numerous studies have shown that the mechanism of cardiac fibrosis involves cardiomyocytes emitting stress signals that trigger inflammatory cell infiltration and cardiac fibroblast activation during cardiac pathological states, such as pressure overload, metabolic dysfunction, or myocardial infarction. The activation of cardiac fibroblasts leads to their differentiation into myofibroblasts and subsequent increase in proliferation, as well as matrix deposition, expression of a rich array of cytokines and growth factors, and formation of fibrous scar tissues. Thus, activated cardiac myofibroblasts are the main effector cells of cardiac fibrosis[33,34], and modulating the signals of early fibroblast activation and late remodeling have obvious therapeutic implications for cardiac fibrosis[35].

Wnt signaling is involved in the process of embryonic development and plays an important role in the dynamic balance of adult tissues. Wnt proteins are secreted ligands that transmit signals across the plasma membrane by interacting with Frizzled receptors and low density lipoprotein receptor-related protein co-receptors $5 / 6$. When Wnt proteins bind to their receptors, a series of intracellular signaling events are induced, including the scaffold protein Axin and glycogen synthase kinase- $3 \beta$ that finally stabilize $\beta$-catenin. $\beta$-Catenin then translocates to the nucleus where it binds to T-cytokines/lymphokines and induces the transcription of Wnt target genes[36, 37]. Duan's team demonstrated that the Wnt signaling pathway plays an important role in the pathogenesis of cardiac fibrosis[19]. Moreover, Huang et al. found that the Wnt/ $\beta$-catenin axis promoted the activation and proliferation of fibroblasts during cardiac fibrosis[38, 39].

Notum, which belongs to the $\alpha / \beta$-hydrolase superfamily, is a Wnt ligand deacylase that can remove the functional palmitoleic acid moiety and act as a secreted feedback antagonist of Wnt[19]. Our results showed that the expression of $\beta$-catenin was significantly increased in a mouse model of myocardial infarction, and cardiac fibroblast fibrosis induced by TGF- $\beta 1$ stimulation. Importantly, intervention with Notum could reverse overexpression of the $\beta$-catenin protein. These results suggest that Notum inhibits the Wnt/ $\beta$-catenin signaling pathway in cardiac fibroblasts, which may be one of the mechanisms of its anti-fibrotic effect.

The mouse model of myocardial infarction is a classical method to induce pathological cardiac fibrosis[40]. Under pathologic conditions, cardiac myofibroblasts secrete extracellular matrix proteins 
(mainly collagen I) that promote progressive cardiac fibrosis[41], as well as the ECM-related fibronectin 1 and a-smooth muscle actin, a marker of the transformation of fibroblasts into myofibroblasts; these are important indicators of fibrosis[42, 43]. Our results showed that, in vivo, intramyocardial injection of Notum downregulated the expression of a-smooth muscle actin and fibronectin 1 in the infarct marginal zone, inhibited the pathological generation of myofibroblasts, and reduced the production of collagen I, thereby mitigating cardiac fibrosis caused by myocardial infarction.

Substantial evidence indicates that TGF- $\beta$ is a key regulatory cytokine causing cardiac fibrosis[44]. TGF$\beta 1$ can initiate the transformation of fibroblasts to myofibroblasts and regulate the expression of collagen and other ECM proteins, ultimately promoting myocardial fibrosis[45]. In vitro, pharmacological intervention with Notum reversed the differentiation of fibroblasts to myofibroblasts induced by TGF- $\beta 1$, inhibited the proliferation and migration of fibroblasts, and post-transcriptionally regulated the expression of collagens $1 \mathbf{a} 1$ and $3 \mathbf{a} 1$. Both the in vitro and in vivo results showed that Notum could regulate the pathological activation of fibroblasts after injury and inhibit the secretion of ECM. In addition to inhibiting the Wnt/ $\beta$-catenin signal pathway, Notum may also be involved in the regulation of other fibrosis-related mechanisms.

Cellular senescence is a stable cell-cycle arrest that can be caused by many physiological and pathological conditions, including oncogene-induced and replicative senescence and can promote tissue remodeling during development and after injury[46, 47]. Senescent cells have their own unique markers, including senescence-related $\beta$-galactosidase activity and up-regulation of proteins, such as p16, p19, p21, and p53. Early studies suggested that aging was a tumor suppressor mechanism. Rayess et al. demonstrated that P16 was a tumor suppressor gene[48]. Furthermore, Zhu's team found that myocardial infarction could induce cardiac fibroblast senescence, inhibit the production of reparative myofibroblasts, interfere with heart repair, and even lead to heart rupture, all of which are related to activation of the p53 signaling pathway[25]. In our study, Notum inhibited the increased p53 expression in cardiac fibroblasts induced by $\mathrm{H}_{2} \mathrm{O}_{2}$ stimulation, and regulated the expression of P21 and P16 at the mRNA level. This indicated that Notum modified the senescence pathway of cardiac fibroblasts. In addition, the results of an immunohistochemical experiment showed that the expression of P16 was inhibited by Notum in the infarct border zone of myocardial infarction mice. This result further reveals the mechanism by which Notum plays a protective role in cardiac fibrosis. Because Notum is an extracellular enzyme, its chemical structure and characteristics have been fully recognized. Specifically, Notum has a well-defined and large active site pocket. Thus, pharmacological interventions utilizing Notum are diverse, and this agent has the potential to be an ideal therapeutic agent.

In conclusion, our present work confirmed the protective effect of Notum on cardiac function in mice with myocardial infarction. In addition, we demonstrated that Notum regulated the Wnt/ $\beta$-catenin pathway and inhibited senescence of cardiac fibroblasts to alleviate their abnormal activation and phenotypic differentiation to myofibroblasts thus inhibiting the occurrence of fibrosis. These findings provide support for a new strategy for the treatment of cardiac fibrosis. 


\section{Declarations}

\section{Declaration of interests}

All authors have no competing interests to declare, financial or otherwise.

\section{Acknowledgments}

This study was supported by the National Natural Science Foundation of China (81900225, 82170299, 81770284); the Major Scientific Fund Project of Heilongjiang Province (ZD2019H001); and the CAMS Innovation Fund for Medical Sciences (CIFMS, 2019-I2M-5-078).

\section{Availability of Data and Materials}

All data that support the findings of this study are available from the corresponding author upon reasonable request.

\section{Author Contributions}

Tianyu Li and Hongli Shan investigated the project application, subject construction and edited the manuscript. Wei Su and Ruonan Fang composed the manuscript, planned the experiments and data management. Ruonan Fang, Yue Li, Liangliang Li, Jing Zhang and Xin Lv performed cellular and molecular biological experiments, conducted data analysis. Wei Su, Qianqian Wang and Guofang Zhang performed animal studies and analyzed the data. Xuelian Li, Hongli Shan and Tianyu Li helped perform the analysis with constructive discussions.

\section{References}

1. Heymans S, Gonzalez A, Pizard A, Papageorgiou AP, Lopez-Andres N, Jaisser F, Thum T, Zannad F and Diez J (2015) Searching for new mechanisms of myocardial fibrosis with diagnostic and/or therapeutic potential. Eur J Heart Fail 17:764-71. doi: 10.1002/ejhf.312

2.Creemers EE and Pinto YM (2011) Molecular mechanisms that control interstitial fibrosis in the pressure-overloaded heart. Cardiovasc Res 89:265-72. doi: 10.1093/cvr/cvq308

3.de Boer RA, De Keulenaer G, Bauersachs J, Brutsaert D, Cleland JG, Diez J, Du XJ, Ford P, Heinzel FR, Lipson KE, McDonagh T, Lopez-Andres N, Lunde IG, Lyon AR, Pollesello P, Prasad SK, Tocchetti CG, Mayr M, Sluijter JPG, Thum T, Tschope C, Zannad F, Zimmermann WH, Ruschitzka F, Filippatos G, Lindsey ML, Maack C and Heymans S (2019) Towards better definition, quantification and treatment of fibrosis in heart failure. A scientific roadmap by the Committee of Translational Research of the Heart Failure Association (HFA) of the European Society of Cardiology. Eur J Heart Fail 21:272-285. doi:

10.1002/ejhf.1406 
4.Shih YC, Chen CL, Zhang Y, Mellor RL, Kanter EM, Fang Y, Wang HC, Hung CT, Nong JY, Chen HJ, Lee TH, Tseng YS, Chen CN, Wu CC, Lin SL, Yamada KA, Nerbonne JM and Yang KC (2018) Endoplasmic Reticulum Protein TXNDC5 Augments Myocardial Fibrosis by Facilitating Extracellular Matrix Protein Folding and Redox-Sensitive Cardiac Fibroblast Activation. Circ Res 122:1052-1068. doi:

10.1161/CIRCRESAHA.117.312130

5.Driesen RB, Nagaraju CK, Abi-Char J, Coenen T, Lijnen PJ, Fagard RH, Sipido KR and Petrov VV (2014) Reversible and irreversible differentiation of cardiac fibroblasts. Cardiovasc Res 101:411-22. doi: $10.1093 / \mathrm{cvr} / \mathrm{cvt338}$

6.Yu J, Seldin MM, Fu K, Li S, Lam L, Wang P, Wang Y, Huang D, Nguyen TL, Wei B, Kulkarni RP, Di Carlo D, Teitell M, Pellegrini M, Lusis AJ and Deb A (2018) Topological Arrangement of Cardiac Fibroblasts Regulates Cellular Plasticity. Circ Res 123:73-85. doi: 10.1161/CIRCRESAHA.118.312589

7.Travers JG, Kamal FA, Robbins J, Yutzey KE and Blaxall BC (2016) Cardiac Fibrosis: The Fibroblast Awakens. Circ Res 118:1021-40. doi: 10.1161/CIRCRESAHA.115.306565

8.Kong P, Christia P and Frangogiannis NG (2014) The pathogenesis of cardiac fibrosis. Cell Mol Life Sci 71:549-74. doi: 10.1007/s00018-013-1349-6

9.Bernaba BN, Chan JB, Lai CK and Fishbein MC (2010) Pathology of late-onset anthracycline cardiomyopathy. Cardiovasc Pathol 19:308-11. doi: 10.1016/j.carpath.2009.07.004

10.Biernacka A and Frangogiannis NG (2011) Aging and Cardiac Fibrosis. Aging Dis 2:158-173.

11.de Couto G, Liu W, Tseliou E, Sun B, Makkar N, Kanazawa H, Arditi M and Marban E (2015) Macrophages mediate cardioprotective cellular postconditioning in acute myocardial infarction. J Clin Invest 125:3147-62. doi: 10.1172/JCI81321

12. Weber KT, Sun Y, Bhattacharya SK, Ahokas RA and Gerling IC (2013) Myofibroblast-mediated mechanisms of pathological remodelling of the heart. Nat Rev Cardiol 10:15-26. doi:

10.1038/nrcardio.2012.158

13.Frangogiannis NG (2012) Regulation of the inflammatory response in cardiac repair. Circ Res 110:15973. doi: 10.1161/CIRCRESAHA.111.243162

14.Blyszczuk P, Berthonneche C, Behnke S, Glonkler M, Moch H, Pedrazzini T, Luscher TF, Eriksson U and Kania G (2013) Nitric oxide synthase 2 is required for conversion of pro-fibrogenic inflammatory CD133(+) progenitors into F4/80(+) macrophages in experimental autoimmune myocarditis. Cardiovasc Res 97:219-29. doi: 10.1093/cvr/cvs317

15.Russell JO and Monga SP (2018) Wnt/beta-Catenin Signaling in Liver Development, Homeostasis, and Pathobiology. Annu Rev Pathol 13:351-378. doi: 10.1146/annurev-pathol-020117-044010 
16.Yang D, Fu W, Li L, Xia X, Liao Q, Yue R, Chen H, Chen X, An S, Zeng C and Wang WE (2017)

Therapeutic effect of a novel Wnt pathway inhibitor on cardiac regeneration after myocardial infarction. Clin Sci (Lond) 131:2919-2932. doi: 10.1042/CS20171256

17.Tao H, Yang JJ, Shi KH and Li J (2016) Wnt signaling pathway in cardiac fibrosis: New insights and directions. Metabolism 65:30-40. doi: 10.1016/j.metabol.2015.10.013

18.Dzialo E, Rudnik M, Koning RI, Czepiel M, Tkacz K, Baj-Krzyworzeka M, Distler O, Siedlar M, Kania G and Blyszczuk P (2019) WNT3a and WNT5a Transported by Exosomes Activate WNT Signaling Pathways in Human Cardiac Fibroblasts. Int J Mol Sci 20. doi: 10.3390/ijms20061436

19.Duan J, Gherghe C, Liu D, Hamlett E, Srikantha L, Rodgers L, Regan JN, Rojas M, Willis M, Leask A, Majesky M and Deb A (2012) Wnt1/betacatenin injury response activates the epicardium and cardiac fibroblasts to promote cardiac repair. EMBO J 31:429-42. doi: 10.1038/emboj.2011.418

20.Xiang FL, Fang M and Yutzey KE (2017) Loss of beta-catenin in resident cardiac fibroblasts attenuates fibrosis induced by pressure overload in mice. Nat Commun 8:712. doi: 10.1038/s41467-017-00840-w

21.Miao J, Liu J, Niu J, Zhang Y, Shen W, Luo C, Liu Y, Li C, Li H, Yang P, Liu Y, Hou FF and Zhou L (2019) Wnt/beta-catenin/RAS signaling mediates age-related renal fibrosis and is associated with mitochondrial dysfunction. Aging Cell 18:e13004. doi: 10.1111/acel.13004

22.Qian L, Hong J, Zhang Y, Zhu M, Wang X, Zhang Y, Chu M, Yao J and Xu D (2018) Downregulation of S100A4 Alleviates Cardiac Fibrosis via Wnt/beta -Catenin Pathway in Mice. Cell Physiol Biochem 46:2551-2560. doi: 10.1159/000489683

23.Jeong MH, Kim HJ, Pyun JH, Choi KS, Lee DI, Solhjoo S, O'Rourke B, Tomaselli GF, Jeong DS, Cho H and Kang JS (2017) Cdon deficiency causes cardiac remodeling through hyperactivation of WNT/betacatenin signaling. Proc Natl Acad Sci U S A 114:E1345-E1354. doi: 10.1073/pnas.1615105114

24.Kakugawa S, Langton PF, Zebisch M, Howell S, Chang TH, Liu Y, Feizi T, Bineva G, O'Reilly N, Snijders AP, Jones EY and Vincent JP (2015) Notum deacylates Wnt proteins to suppress signalling activity. Nature 519:187-192. doi: 10.1038/nature14259

25.Pentinmikko N, Iqbal S, Mana M, Andersson S, Cognetta AB, 3rd, Suciu RM, Roper J, Luopajarvi K, Markelin E, Gopalakrishnan S, Smolander OP, Naranjo S, Saarinen T, Juuti A, Pietilainen K, Auvinen P, Ristimaki A, Gupta N, Tammela T, Jacks T, Sabatini DM, Cravatt BF, Yilmaz OH and Katajisto P (2019) Notum produced by Paneth cells attenuates regeneration of aged intestinal epithelium. Nature 571:398402. doi: 10.1038/s41586-019-1383-0

26.Cai B, Tan X, Zhang Y, Li X, Wang X, Zhu J, Wang Y, Yang F, Wang B, Liu Y, Xu C, Pan Z, Wang N, Yang B and Lu Y (2015) Mesenchymal Stem Cells and Cardiomyocytes Interplay to Prevent Myocardial Hypertrophy. Stem Cells Transl Med 4:1425-35. doi: 10.5966/sctm.2015-0032 
27.Ma H, Killaars AR, DelRio FW, Yang C and Anseth KS (2017) Myofibroblastic activation of valvular interstitial cells is modulated by spatial variations in matrix elasticity and its organization. Biomaterials 131:131-144. doi: 10.1016/j.biomaterials.2017.03.040

28.Sapudom J, Rubner S, Martin S, Thoenes S, Anderegg U and Pompe T (2015) The interplay of fibronectin functionalization and TGF-beta1 presence on fibroblast proliferation, differentiation and migration in 3D matrices. Biomater Sci 3:1291-301. doi: 10.1039/c5bm00140d

29.Nagaraju CK, Robinson EL, Abdesselem M, Trenson S, Dries E, Gilbert G, Janssens S, Van Cleemput J, Rega F, Meyns B, Roderick HL, Driesen RB and Sipido KR (2019) Myofibroblast Phenotype and Reversibility of Fibrosis in Patients With End-Stage Heart Failure. J Am Coll Cardiol 73:2267-2282. doi: 10.1016/j.jacc.2019.02.049

30.Voss AK, Krebs DL and Thomas T (2006) C3G regulates the size of the cerebral cortex neural precursor population. EMBO J 25:3652-63. doi: 10.1038/sj.emboj.7601234

31.Detienne G, De Haes W, Mergan L, Edwards SL, Temmerman L and Van Bael S (2018) Beyond ROS clearance: Peroxiredoxins in stress signaling and aging. Ageing Res Rev 44:33-48. doi: 10.1016/j.arr.2018.03.005

32.Gourdie RG, Dimmeler S and Kohl P (2016) Novel therapeutic strategies targeting fibroblasts and fibrosis in heart disease. Nat Rev Drug Discov 15:620-638. doi: 10.1038/nrd.2016.89

33.Porter KE and Turner NA (2009) Cardiac fibroblasts: at the heart of myocardial remodeling. Pharmacol Ther 123:255-78. doi: 10.1016/j.pharmthera.2009.05.002

34.Frangogiannis NG (2019) Cardiac fibrosis: Cell biological mechanisms, molecular pathways and therapeutic opportunities. Mol Aspects Med 65:70-99. doi: 10.1016/j.mam.2018.07.001

35.van Nieuwenhoven FA and Turner NA (2013) The role of cardiac fibroblasts in the transition from inflammation to fibrosis following myocardial infarction. Vascul Pharmacol 58:182-8. doi:

10.1016/j.vph.2012.07.003

36.Logan CY and Nusse R (2004) The Wnt signaling pathway in development and disease. Annu Rev Cell Dev Biol 20:781-810. doi: 10.1146/annurev.cellbio.20.010403.113126

37.Nusse R and Clevers H (2017) Wnt/beta-Catenin Signaling, Disease, and Emerging Therapeutic Modalities. Cell 169:985-999. doi: 10.1016/j.cell.2017.05.016

38. Huang $\mathrm{H}$ and $\mathrm{HeX}$ (2008) Wnt/beta-catenin signaling: new (and old) players and new insights. Curr Opin Cell Biol 20:119-25. doi: 10.1016/j.ceb.2008.01.009

39.Huang C and Ogawa R (2012) Fibroproliferative disorders and their mechanobiology. Connect Tissue Res 53:187-96. doi: 10.3109/03008207.2011.642035 
40.Fu X, Khalil H, Kanisicak O, Boyer JG, Vagnozzi RJ, Maliken BD, Sargent MA, Prasad V, Valiente-Alandi I, Blaxall BC and Molkentin JD (2018) Specialized fibroblast differentiated states underlie scar formation in the infarcted mouse heart. J Clin Invest 128:2127-2143. doi: 10.1172/JCI98215

41.Leask A (2015) Getting to the heart of the matter: new insights into cardiac fibrosis. Circ Res 116:1269-76. doi: 10.1161/CIRCRESAHA.116.305381

42.Pattabiraman PP, Maddala R and Rao PV (2014) Regulation of plasticity and fibrogenic activity of trabecular meshwork cells by Rho GTPase signaling. J Cell Physiol 229:927-42. doi: 10.1002/jcp.24524

43.Shinde AV, Humeres $C$ and Frangogiannis NG (2017) The role of alpha-smooth muscle actin in fibroblast-mediated matrix contraction and remodeling. Biochim Biophys Acta Mol Basis Dis 1863:298309. doi: 10.1016/j.bbadis.2016.11.006

44.Bujak M and Frangogiannis NG (2007) The role of TGF-beta signaling in myocardial infarction and cardiac remodeling. Cardiovasc Res 74:184-95. doi: 10.1016/j.cardiores.2006.10.002

45.Khan R and Sheppard R (2006) Fibrosis in heart disease: understanding the role of transforming growth factor-beta in cardiomyopathy, valvular disease and arrhythmia. Immunology 118:10-24. doi: 10.1111/j.1365-2567.2006.02336.x

46. Hernandez-Segura A, Nehme J and Demaria M (2018) Hallmarks of Cellular Senescence. Trends Cell Biol 28:436-453. doi: 10.1016/j.tcb.2018.02.001

47.Hoare M and Narita M (2013) Transmitting senescence to the cell neighbourhood. Nat Cell Biol 15:887-9. doi: 10.1038/ncb2811

48. Rayess H, Wang MB and Srivatsan ES (2012) Cellular senescence and tumor suppressor gene p16. Int J Cancer 130:1715-25. doi: 10.1002/ijc.27316

\section{Figures}


A
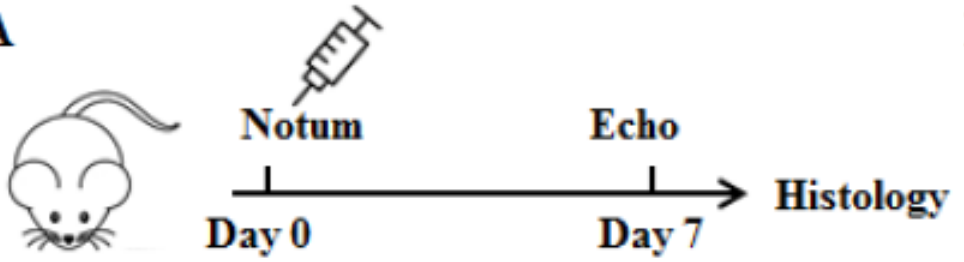

LAD ligation

B

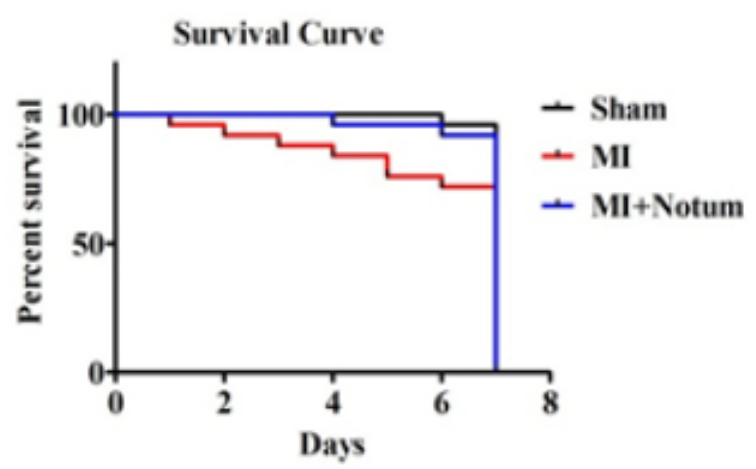

C

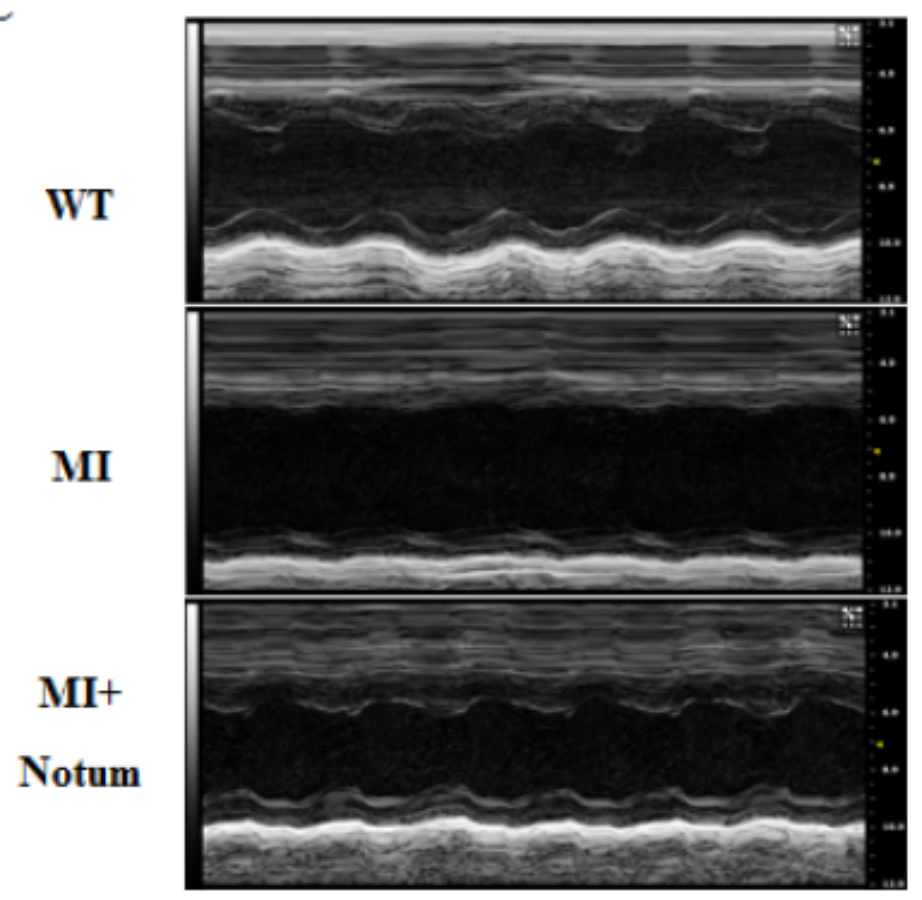

D

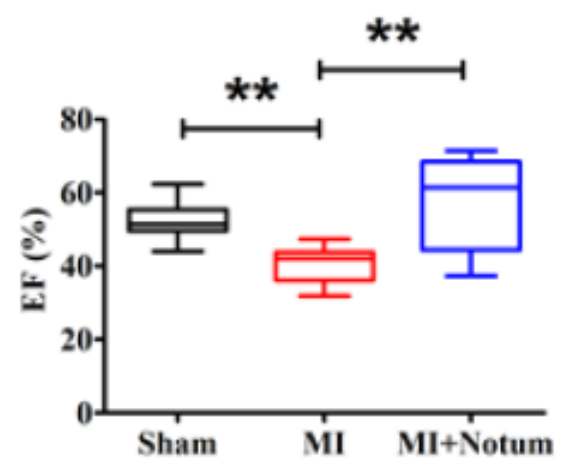

$\mathbf{F}$

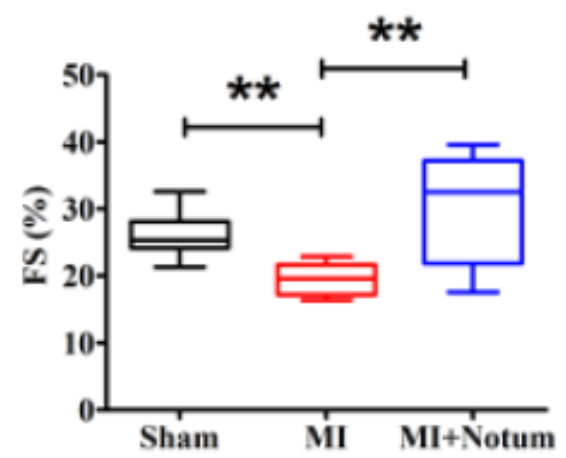

G
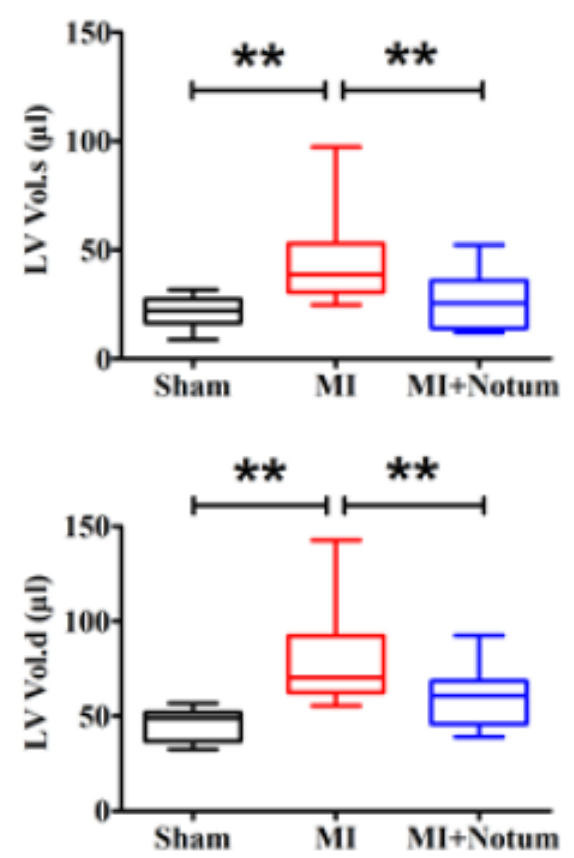

\section{Figure 1}

Notum increases survival and improves cardiac function in MI mice.(A) Experimental protocal for treatment with Notum. (B) Survival curve of mice as indicated group. (C) Echocardiography was applied to evaluate the heart function of MI mice after treatment with Notum $(n=5)$, indicated as ejection fraction (EF) (D), fraction shortening (FS) (E), left ventricular systolic volume (Lv.vol.s) (F) and left ventricular 
diastolic volume (Lv.vol.d) (G). All data are presented as mean \pm SEM. ${ }^{* * P}<0.01$. Survival distributions were estimated by the Kaplan-Meier method and compared by log-rank test.

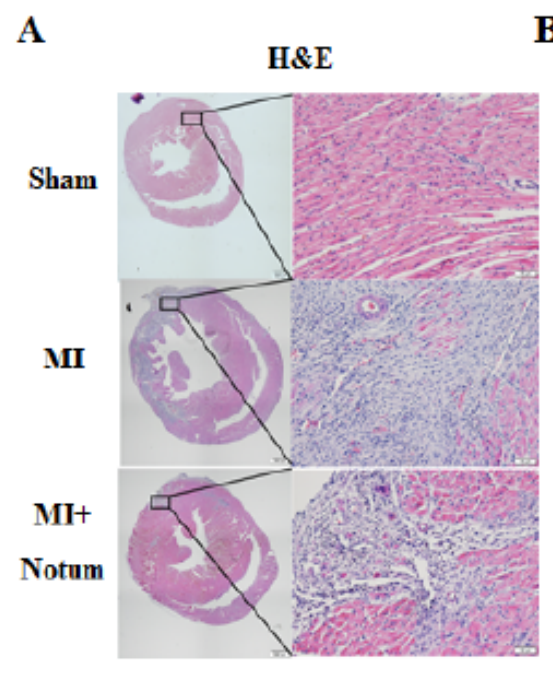

C

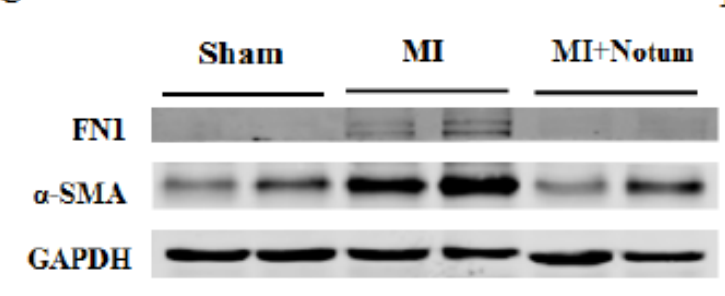

B

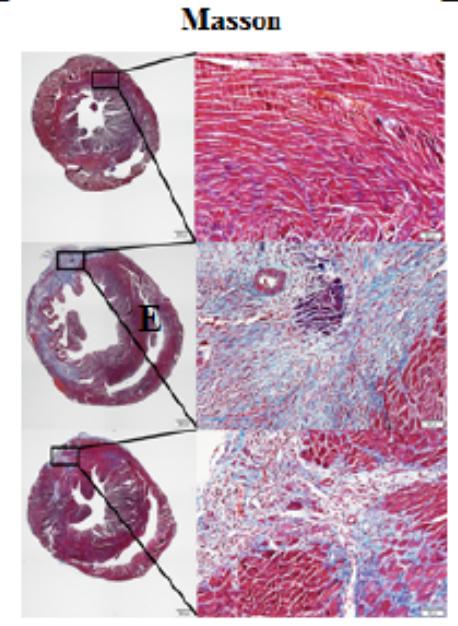

$\mathbf{F}$
D
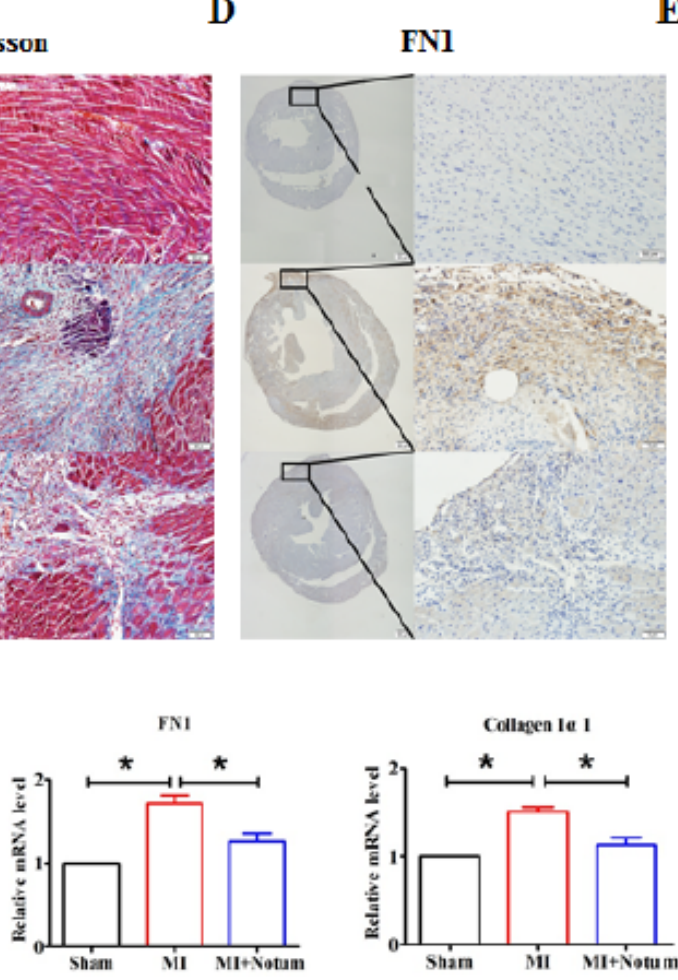

$\mathbf{E}$

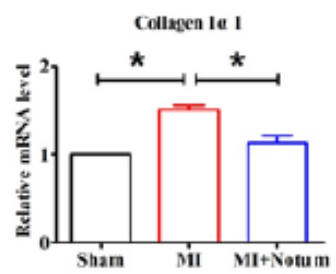

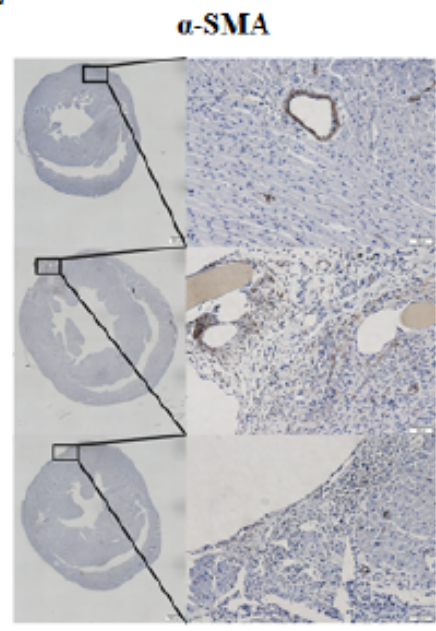

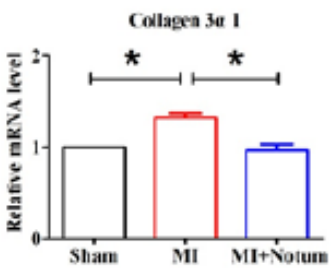

\section{Figure 2}

Notum attenuates MI-induced cardiac fibrosis. (A-B) Representative images of H\&E and Masson's trichrome-stained sections. On the left is the whole heart section. Scale bars, $500 \mu m$. The right is partial enlarged view. Scale bars, 50 m . n=5-7. (C)Western blot analysis of fibrosis related proteins (FN1 and aSMA) in the hearts. $n=5-6$. (D-E) Immunohistochemistry staining of FN1 and a-SMA in sham, MI and $\mathrm{Ml+Notum}$ mice. On the left is the whole heart section. Scale bars, $500 \mu \mathrm{m}$. The right is partial enlarged

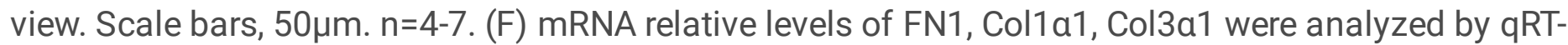
PCR. $n=5-6, * P<0.01$ vs. Sham or MI. All data are presented as mean \pm SEM. 
A

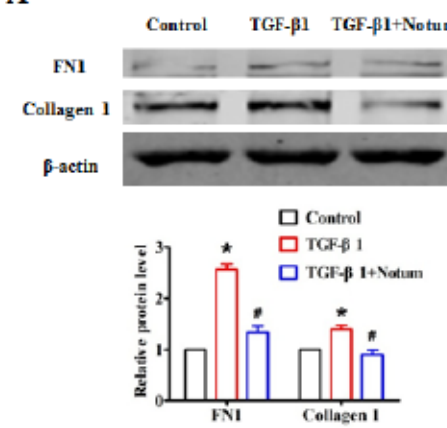

B

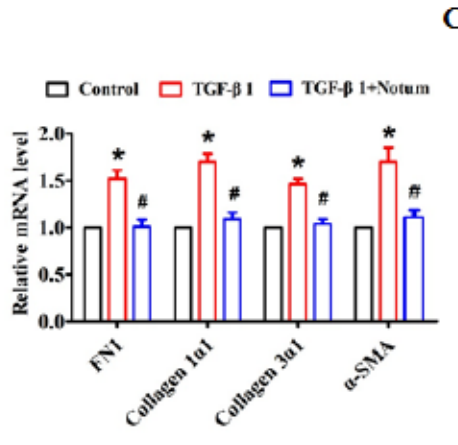

C

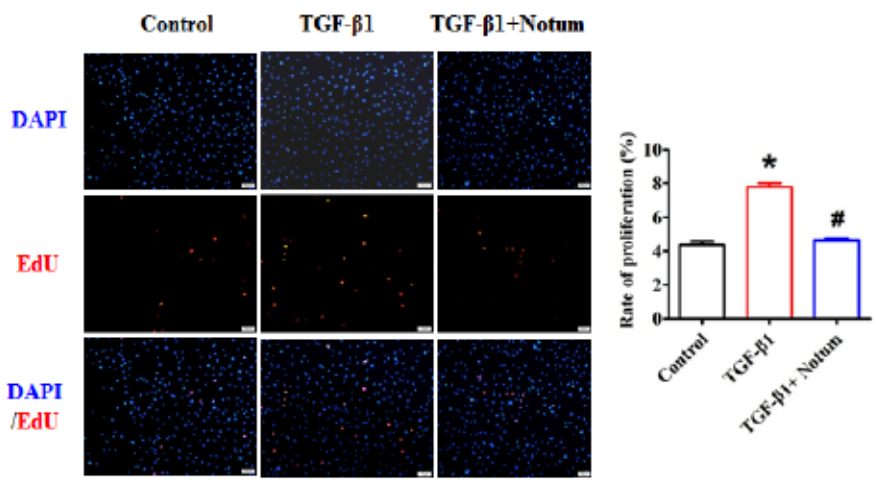

D

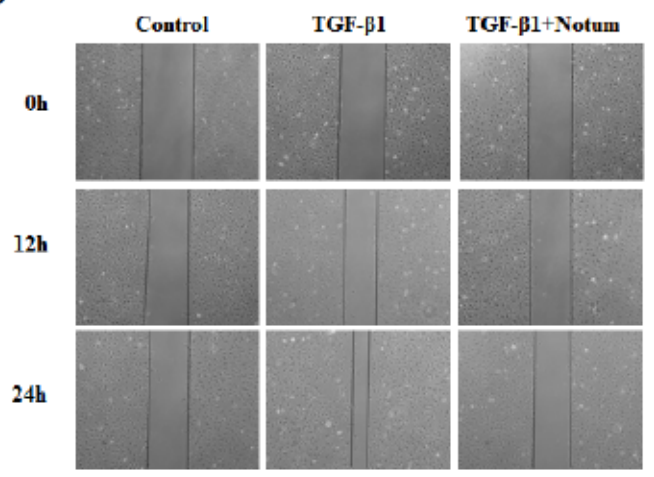

$\square$ Control $\square$ TGF- $1 \square$ TGF- 1+ Notum

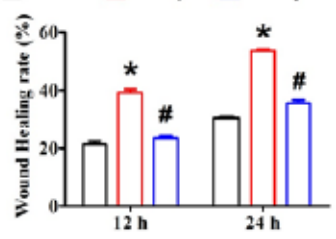

$\mathbf{E}$

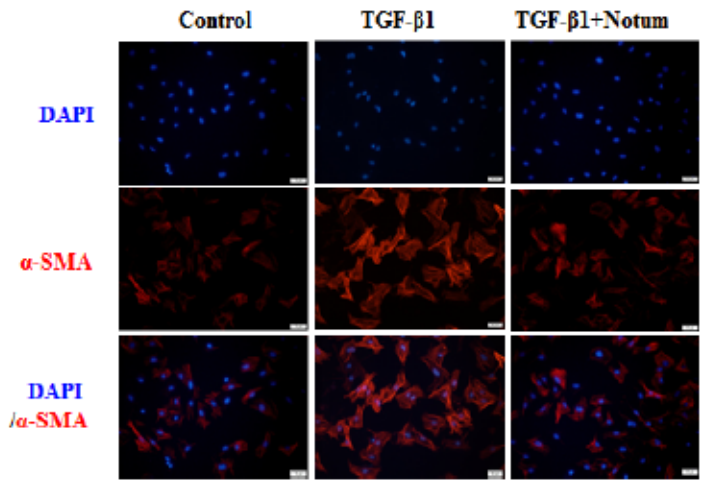

\section{Figure 3}

Notum abrogates cardiac fibroblasts activation induced by TGF- $\beta 1$. (A) Western blot analysis of FN1 and Collagen 1 in cardiac fibroblasts after 24 hours treatment of TGF- $\beta 1$ and Notum. $n=6$ (B) qRT-PCR analysis of the expression of FN1, Col 1a1, Col $3 a 1$ and a-SMA in cardiac fibroblasts. $n=5-6$ (C) EDU staining demonstrates the effect of Notum on TGF- $\beta 1$-induced cardiac fibroblasts proliferation. Scale bars, $50 \mu \mathrm{m} . n=8$ (D) Wound healing scratch assay evaluates the effect of Notum on TGF- $\beta 1$-induced migration in cardiac fibroblasts. Scale bars, $200 \mu \mathrm{m} . n=8$ (E) Effect of Notum on cardiac fibroblastmyofibroblast transition, as measured by immunofluorescence. Scale bars, $50 \mu \mathrm{m}$. All data are presented as mean $\pm \mathrm{SEM}$. ${ }^{*} \mathrm{P}<0.01$ vs. $\mathrm{CTL} ; \mathrm{PP}<0.01$ vs. TGF- $\beta 1$.

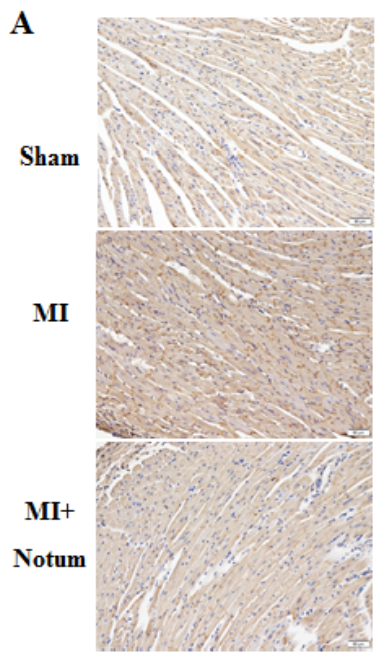

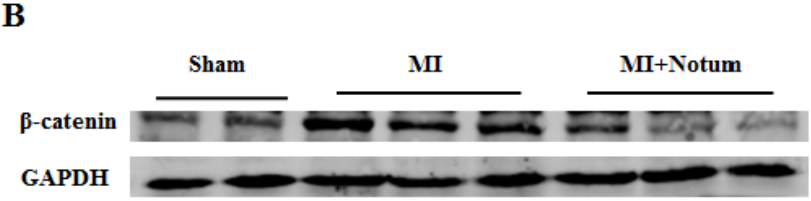

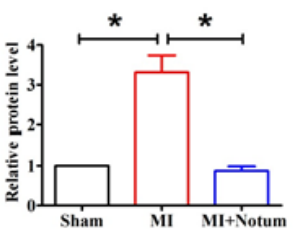

D

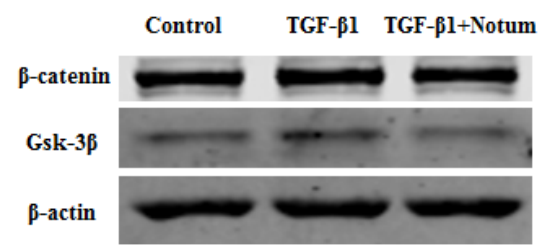

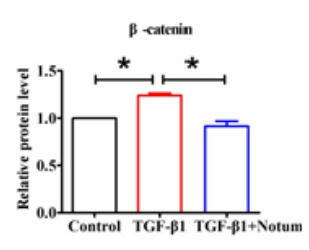
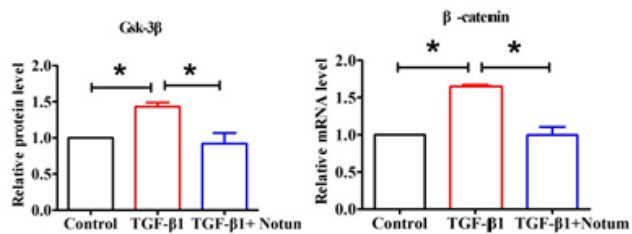
Figure 4

Notum inhibits Wnt/ $\beta$-catenin signaling activation in cardiac fibroblasts. (A) Immunohistochemistry analysis showed decreased protein expression of $\beta$-catenin in Ml+Notum-treated mice compared MI mice.

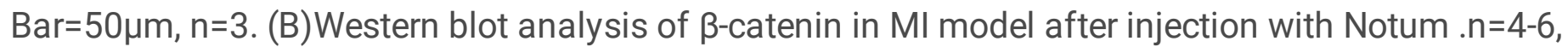
${ }^{*} P<0.01$ (C) The mRNA level of $\beta$-catenin was detected by qRT-PCR in mice. $n=6,{ }^{*}<0.01$ vs. Sham or MI. (D) The protein levels of $\beta$-catenin and GSK-3 $\beta$ were measured by Western blot in TGF- $\beta 1$-induced cardiac fibrogenesis after Notum treatment. $n=3-5,{ }^{*}<0.01$ vs. Control or TGF- $\beta 1$ (E) qRT-PCR analysis of the expression of $\beta$-catenin in vitro. $n=3, * P<0.01$. All data are presented as mean $\pm S E M$.

A

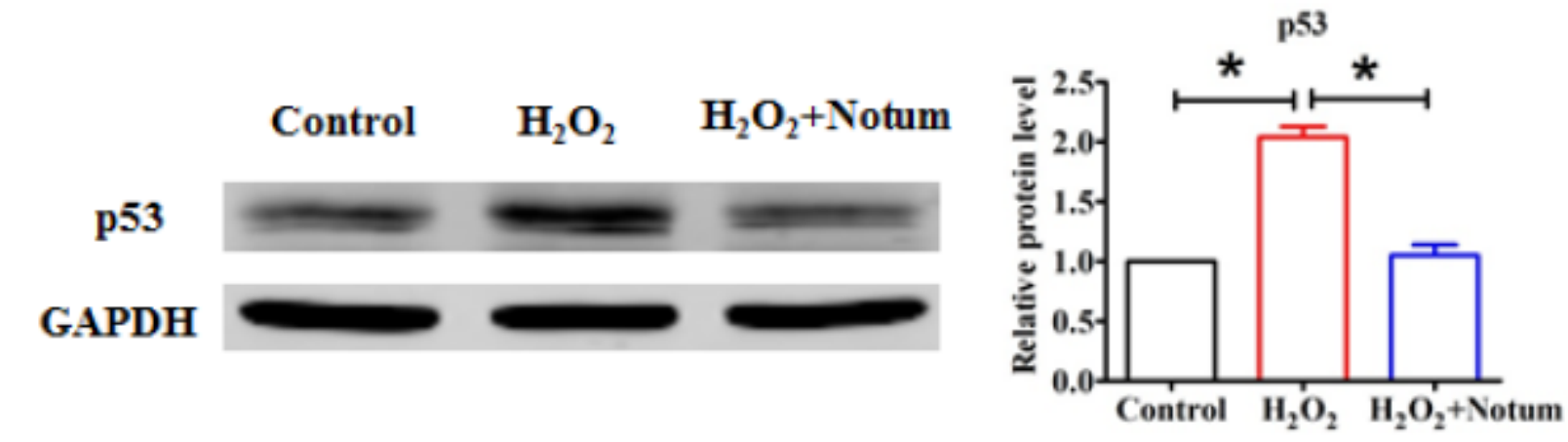

B

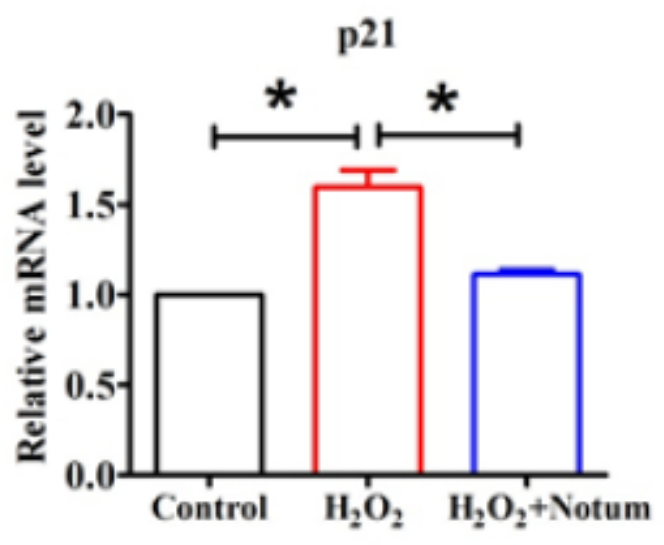

C

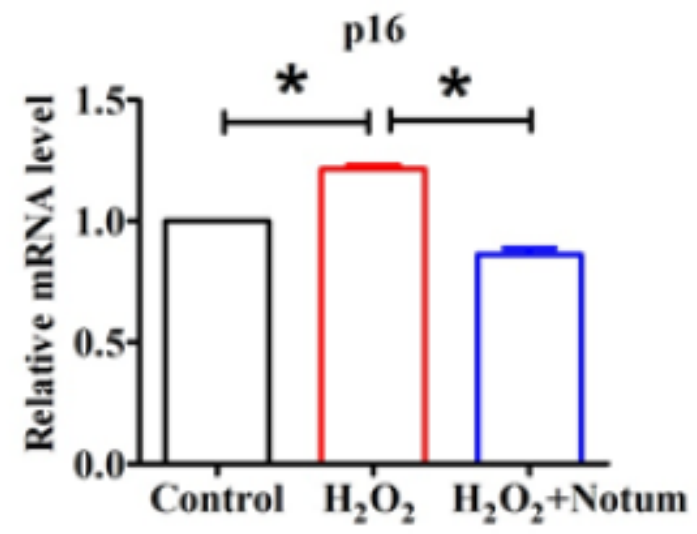

D

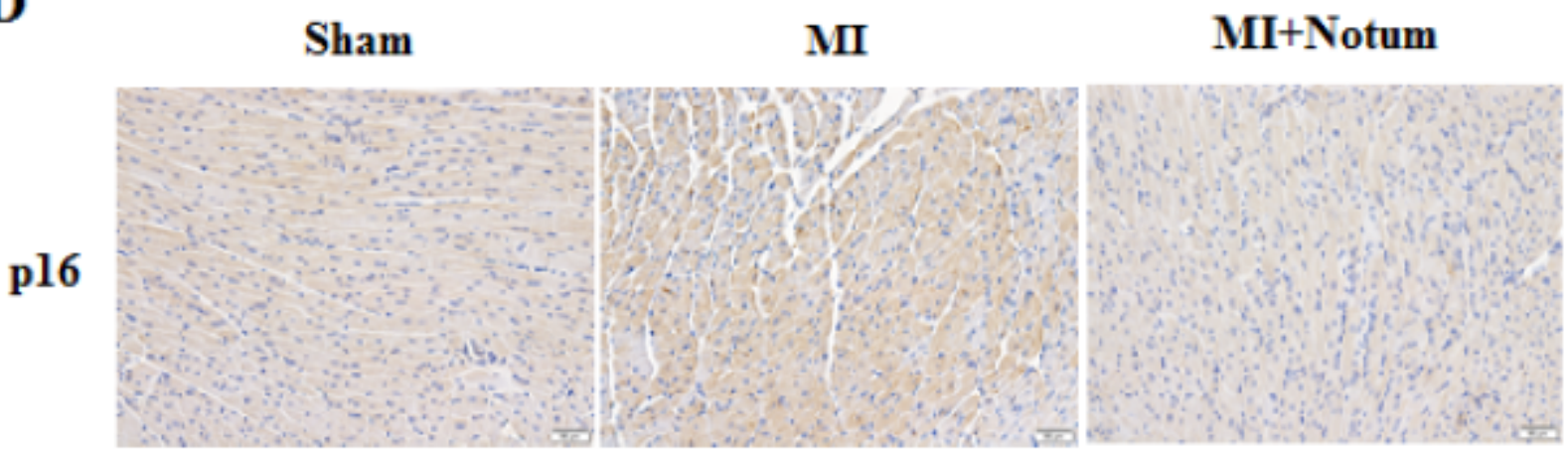

Figure 5 
The effect of Notum on cardiac fibroblasts senescence. (A) Western blot evaluates the protein level of p53 in cardiac fibroblasts treated with $\mathrm{H} 2 \mathrm{O} 2$ for $2 \mathrm{~h}$ after $22 \mathrm{~h}$ treatment of Notum. $\mathrm{n}=5,{ }^{*} \mathrm{P}<0.01$. (B) \& (C) mRNA relative levels of p21 and p16 were analyzed by qRT-PCR. $n=3-5, * P<0.01$ (D) Immunohistochemcal staining shows the expression changes of $p 16$ in mice. Scale bars, $50 \mu \mathrm{m}$. $n=4-5$, All data are presented as mean \pm SEM.

\section{Stimulate}

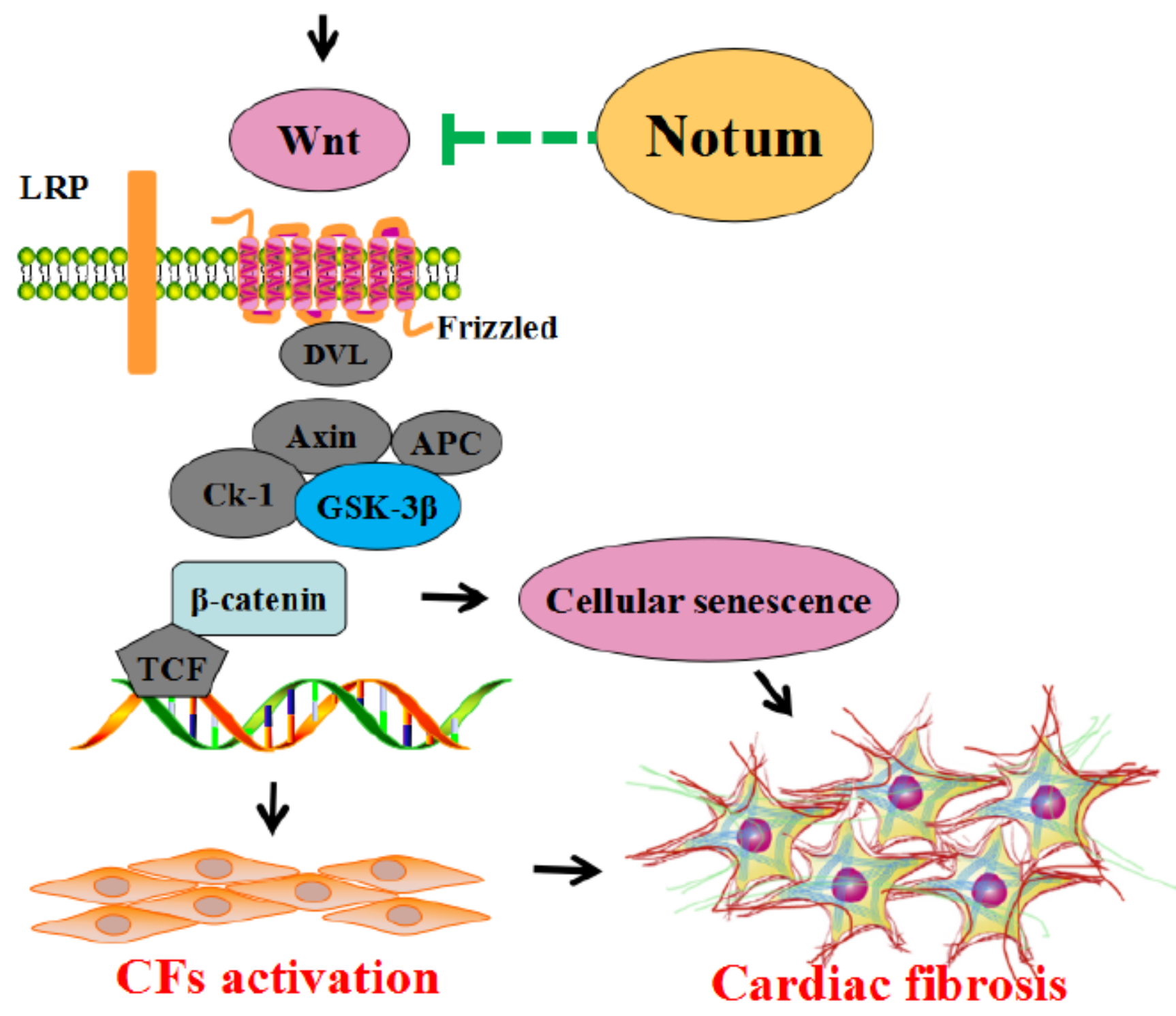

Figure 6

Schematic diagram for the proposed mechanism involving in the anti-fibrotic effect of Notum in heart. 